\title{
Clinical and Radiologic Disease Activity in Pregnancy and Postpartum in MS
}

Annika Anderson, BA, Kristen M. Krysko, MD, MAS, Alice Rutatangwa, DO, MSc, Tanya Krishnakumar, BA, Chelsea Chen, William Rowles, BA, Chao Zhao, MS, Maria K. Houtchens, MD, and Riley Bove, MD, MSc

Neurol Neuroimmunol Neuroinflamm 2021;8:e959. doi:10.1212/NXI.0000000000000959

\section{Abstract}

\section{Objective}

To evaluate radiologic and clinical inflammatory activity in women with MS during pregnancy and postpartum.

\section{Methods}

We performed a retrospective analysis of prospectively collected clinical and MRI reports for women who became pregnant while followed at the University of California, San Francisco MS Center between 2005 and 2018. Proportion of brain MRIs with new T2-hyperintense or gadolinium enhancing $(\mathrm{Gd}+)$ lesions (primary outcome) and annualized relapse rate (ARR; secondary) were compared before and after pregnancy.

\section{Results}

We identified 155 pregnancies in 119 women (median Expanded Disability Status Scale [EDSS] 2.0). For the 146 live birth pregnancies, prepregnancy ARR was 0.33; ARR decreased during pregnancy, particularly the third trimester (ARR $0.10, p=0.017$ ) and increased in the 3 months postpartum (ARR 0.61, $p=0.012$ ); and $16 \%$ of women experienced a clinically meaningful increase in EDSS. Among 70 pregnancies with paired brain MRIs available, $53 \%$ had new T2 and/or Gd+ lesions postpartum compared with $32 \%$ prepregnancy $(p<0.001)$. Postpartum clinical relapses were associated with $\mathrm{Gd}+$ lesions $(p<0.001)$. However, even for patients without postpartum relapses, surveillance brain MRIs revealed new T2 and/or Gd+ lesions in $31 \%$. Protective effects of exclusive breastfeeding for $\geq 3$ months (odds ratio $=0.3$, 95\% confidence interval 0.1-0.9) were observed for relapses.

\section{Conclusions}

Building on previous reports of increased relapse rate in the first 3 months postpartum, we report a significant association between inflammation on MRI and this clinical activity. We also detected postpartum radiologic activity in the absence of relapses. Both clinical and radiologic reassessment may inform optimal treatment decision-making during the high-risk early postpartum period.

\author{
Correspondence \\ Dr. Bove \\ riley.bove@ucsf.edu
}




\section{Glossary}

ARR = annualized relapse rate $\mathbf{C I}=$ confidence interval; $\mathbf{D M T}=$ disease modifying therapy; $\mathbf{E D S S}=$ Expanded Disability Status Scale; $\mathbf{E M R}=$ electronic medical record; $\mathbf{G d}+$ = gadolinium enhancing; $\mathbf{I Q R}=$ interquartile range; $\mathbf{m A b}=$ monoclonal antibody; OR = odds ratio; UCSF = University of California, San Francisco.

MS typically begins between the ages of $20-40$ years and has a female-to-male ratio of $3: 1 .^{1-3}$ As such, MS is primarily diagnosed in women of reproductive age. Several studies have demonstrated that women experience fewer MS relapses during the immunotolerant state of pregnancy; however, an increase in relapses has been observed postpartum. ${ }^{4-6}$ Recent exceptions to this trend are notable. First, in the diseasemodifying therapy (DMT) era, women discontinuing DMTs interfering with lymphocyte trafficking (fingolimod and natalizumab) have increased relapse risk during pregnancy due to 'rebound' disease activity. ${ }^{7}$ Second, in a more clinically benign population-based cohort, fewer women were noted to experience relapses postpartum. ${ }^{8}$ Third, exclusive breastfeeding has been associated with reduced postpartum relapses. ${ }^{9,10}$

Because clinical inflammatory activity postpartum could be confused with other common neurologic conditions (such as migraines, ${ }^{11}$ meralgia paresthetica, ${ }^{12}$ or DeQuervain tenosynovitis $^{13}$ ), MRI detects new inflammatory lesions objectively. Three small neuroimaging studies have reported increased inflammatory activity postpartum: a cohort of 28 Finnish women with $\mathrm{MS},{ }^{14}$ women with radiologically isolated syndrome, ${ }^{15}$ and a report of 2 patients with MS. ${ }^{16}$ There is a need for larger case series of MRI-defined postpartum inflammatory activity.

In the current study, we evaluated inflammatory activity on brain MRIs of women with MS during pregnancy and postpartum (primary) and clinical relapses (secondary). We hypothesized that inflammatory activity was increased radiologically and clinically postpartum and that exclusive breastfeeding was associated with a reduction in the rate of both outcomes.

\section{Methods}

\section{Sample Selection}

In this retrospective analysis of prospectively collected clinical data, we screened the electronic medical record (EMR) to identify women followed at the University of California, San Francisco (UCSF) MS and Neuroinflammation Center who became pregnant between 2015 and 2018 and for whom prospectively recorded clinical data were available. We identified 88 women with 103 pregnancies; we also included 13 additional pregnancies for these women that preceded the search window (2005-2015). From a separate study chart review, we included an additional 39 pregnancies between 2005 and 2015 from 31 women. Altogether, we identified 119 women, with 155 pregnancies. Women participating in an ongoing prospective pregnancy registry that began in 2018 were excluded $(\mathrm{N}=56$ as of July 15,2020$)$.

\section{Standard Protocol Approvals, Registrations, and Patient Consents}

The UCSF Committee of Human Research approved the study protocol for retrospective analysis of EMR-derived MS data with no patient contact (Ref \#13-11686).

\section{Data Collection}

Maternal MS clinical history was extracted from medical records, including year of MS onset, disease course at conception, Expanded Disability Status Scale (EDSS) score, clinical relapses, and DMT use from the 12-month preconception to the 12 months after delivery or pregnancy loss. Both prescription records and clinician notes were reconciled during chart review to determine DMT use. Clinical relapses were defined as new or worsening neurologic symptoms for at least 24 hours in the absence of fever or infection, as documented in clinical records by the treating neurologist. When EDSS was not explicitly included in the treating neurologist's note, this was extrapolated from the neurologic examination, documented symptoms, and reported ambulatory abilities by a neurologist (K.M.K.), blinded to timing of the EDSS regarding pregnancy. Any use of prophylactic steroids (prescribed, for example, when delaying DMT initiation postpartum to allow breastfeeding, but not after a clinical relapse) during this timeframe was also recorded.

Neuroradiology reports for brain MRIs, as well as spinal cord (cervical and thoracic) MRIs when available, performed during the time interval from 12-month preconception to 12 months after delivery were collected. Neuroimaging reports for MS-related brain and spinal cord MRIs were manually reviewed for the presence of T2-weighted hyperintense lesions that were new relative to a previous MRI and of gadolinium enhancing $(\mathrm{Gd}+)$ lesions when contrast was administered. In some cases (24\% brain and $29 \%$ overall), MRIs were performed and interpreted outside of UCSF; the neuroimaging report and/or UCSF clinician's note were used to identify new T2 and Gd + lesions in these cases. Clinical indication for the MRI was categorized as either "monitoring" (surveillance, treatment planning, or treatment monitoring) or "new symptom" based on clinical notes and/or imaging orders.

Obstetrical data, collected from medical record review for the study pregnancies, included gravidity and parity preconception, use of assisted reproductive technologies, 
pregnancy complications, gestational age at delivery or pregnancy loss, infant sex, and breastfeeding status (exclusive, nonexclusive, or not at all) up to 12 months after delivery. To minimize the risk of overestimating the impact of breastfeeding on clinical outcomes, breastfeeding was assumed to be nonexclusive unless explicitly indicated to be exclusive by the neurologist's or obstetrician's notes in the EMR. Duration of exclusive breastfeeding was also collected, and based on previous reports, women were categorized as "exclusive breastfeeding" if they did so for at least 3 months ${ }^{17}$; pregnancies with shorter duration of exclusive breastfeeding, nonexclusive breastfeeding, or no breastfeeding were together categorized as "not exclusive breastfeeding."

\section{Statistical Analyses}

Descriptive statistics were reported with mean and SD, median, interquartile range (IQR) and range, or frequency, as appropriate. For pregnancies resulting in live births, we then carried out further analyses.

To determine how MS inflammatory activity changes with pregnancy, we evaluated MRI activity by the proportion of MRIs demonstrating new T2 hyperintense and/or Gd+ lesions ("active MRI") and clinical activity by the annualized relapse rate (ARR). Our primary outcome was difference in MRI inflammatory activity postpartum relative to before; we performed a number of other exploratory analyses. We calculated proportion of active MRIs and ARR for each threemonth period ("trimester") in the year preconception, during pregnancy, and in the year postpartum.

We compared the number of clinical relapses for each trimester during and after pregnancy to the year preconception using a mixed-effects negative binomial regression model with a random person-specific relapse rate, accounting for the repeated measures nature of the data and multiple pregnancies occurring in some women. The outcome in the model was relapse count with an offset by the natural log of disease duration. ARR was calculated from the model and parameterized as $\exp$ (constant + beta) for each time period. We also performed sensitivity analyses for ARR for these time periods in 2 conditions: excluding pregnancies (1) with deliveries before 2010 and (2) in women treated with fingolimod or natalizumab preconception.

For women with MRIs available both before and after pregnancy, we compared the proportion of pregnancies with active brain MRIs (new T2 and/or Gd+ lesions) in the year postpartum with those of the year before pregnancy, using conditional logistic regression, accounting for women who contributed more than one pregnancy; determination of yes/no activity was based on all MRIs available for each time period. We evaluated the relationship between postpartum clinical relapse and MRI activity (new $\mathrm{Gd}+$ lesions) when performed within 60 days of symptom onset using univariable logistic regression for both the first trimester and the entire year postpartum.

We also evaluated for a clinically meaningful worsening in EDSS from prepregnancy baseline to last available within 12 months of delivery (for baseline score of 0: 1.5-point increase; baseline score 1.0-5.5: 1.0-point increase; baseline score $\geq 6$ : 0.5 -point increase, as previously defined ${ }^{18}$ ). EDSS scores within 30 days after a clinical relapse were not included.

We evaluated for predictors of clinical relapse in the first trimester postpartum using univariable logistic regression. We included:

- disease duration and maternal age at conception, given a priori relationships with inflammatory risk

- factors previously related to postpartum inflammatory activity: ARR in the year before pregnancy, relapses during pregnancy (no relapses vs $\geq 1$ relapse), ${ }^{5}$ and breastfeeding status (nonexclusive vs exclusive for at least 3 months) ),10 $^{\text {, }}$

- treatment factors: prophylactic steroid use, DMT in the year preconception, and DMT initiation in the 3 months postpartum, each evaluated as any use vs no use.

To evaluate predictors of brain MRI activity (new Gd+ lesions) in the first trimester postpartum, we performed similar univariable logistic regressions, with the exception that we additionally included the occurrence of a new Gd+ lesion in the year before pregnancy, and we determined breastfeeding status (nonexclusive vs exclusive) and DMT initiation up to the time of MRI.

Based on previous findings in reported case series, we also evaluated additional clinical scenarios. We evaluated the association of early initiation of postpartum DMT (use vs nonuse) in the first 3 months from delivery with ARR (independent sample $t$-test) and development of Gd+ lesions on MRI brain (univariable logistic regression) in the second and third postpartum trimesters.

To describe use of prophylactic steroids, we qualitatively assessed relapses across the first 2 trimesters (i.e., months zero to 6) postpartum in women receiving prophylactic steroids and breastfeeding for at least 3 months. We also qualitatively evaluated relapses and MRI activity in the subset of women who used anti-CD20 monoclonal antibody $(\mathrm{mAb})$ therapies before conception and postpartum.

Alpha was set at 0.05 , and all tests were two sided. The mixedeffects negative binomial regression was performed in STATA 15 (College Station, TX). All other analyses were performed with JMP Pro software version 15.0.0. We did not adjust for multiple comparisons because of the exploratory nature of secondary analyses.

\section{Data Availability}

Deidentified data will be shared with any qualified investigator by request.

\section{Results}

\section{Characteristics of the Study Cohort}

A total of 155 pregnancies in 119 women were included. All pregnancies identified in the EMR had follow-up clinical data 
available for the entirety of their pregnancy; 145 had at least 3 months of postpartum follow-up. The 119 women contributed 1 $(\mathrm{n}=90), 2(\mathrm{n}=22)$, or $3(\mathrm{n}=7)$ pregnancies; 3 of these women contributed a twin pregnancy each. Baseline characteristics were typical for a pregnancy cohort, with a mean age of 33 years at conception and median EDSS of 2.0 (table 1). In 109 pregnancies, the mother received DMT in the year before conception. DMT was stopped before conception in 51 pregnancies, during the first or second trimester in 49 , and continued throughout pregnancy for $9(\mathrm{~N}=8$ glatiramer acetate; $\mathrm{N}=1$ elected termination to continue with natalizumab infusions).

After delivery, there were various treatment approaches. For the 145 live births with first trimester postpartum data, in 26 women, DMT was initiated within 3 months of delivery without breastfeeding; in 81 women, DMT was deferred for breastfeeding (exclusively [ $\mathrm{N}=49]$ or nonexclusively [ $\mathrm{N}=$ 32]); and 9 women initiated glatiramer acetate while breastfeeding (exclusively $[\mathrm{N}=2]$ and nonexclusively $[\mathrm{N}=7]$ ). For 29 pregnancies, there was no initiation of DMT or breastfeeding (for $\geq 3$ months) in the first trimester postpartum.

Brain MRIs were available for 97 pregnancies in the year before conception, and for 137 women in the year postpartum (among 105 live-birth pregnancies; 134 with gadolinium, table e-1, lww.com/NXI/A414), with mean (SD) time of first MRI since delivery of 5.6 (3.6) months. Most (107) of the 137 postpartum MRIs had been obtained for monitoring purposes (104 with any previous MRI for comparison), and 30 in response to changes in symptoms. In 70 pregnancies, brain MRIs were available from both the year before $(\mathrm{N}=85)$ and after pregnancy $(\mathrm{N}=94)$. The smaller number of postpartum cervical $(\mathrm{N}=51)$ and thoracic spine $(\mathrm{N}=18)$ MRIs, or brain MRIs from pregnancies that did not result in live births $(\mathrm{N}=$ 6) precluded statistical analysis. There were no differences in age, MS duration, or ARR between the women who did and did not have paired MRIs available.

\section{Pregnancy Outcomes}

Among the 155 pregnancies, 146 resulted in a live birth -133 at term and 13 prematurely (table 1$)$. Reasons for pregnancy loss $(\mathrm{N}=9)$ included spontaneous abortion $(\mathrm{N}=6)$, elective termination $(\mathrm{N}=2)$, and stillbirth $(\mathrm{N}=1)$. Women experiencing pregnancy loss or termination did not differ in age, disease duration, or EDSS from women who experienced live births ( $p>$ 0.05 in independent sample $t$-tests). In the 6 cases of spontaneous abortion, treatment included none $(\mathrm{N}=3)$, rituximab $(\mathrm{N}$ $=2,23$, and 30 weeks before conception), and glatiramer acetate $(\mathrm{N}=1$, stopped 6 weeks after conception). One woman experienced a stillbirth at $39 \mathrm{w} 1 \mathrm{~d}$ (etiology not available) and had received an ocrelizumab infusion 10 weeks before conception.

Among the 146 live-birth pregnancies, mean gestational age (SD) at delivery was $39.2(1.8)$ weeks (available $\mathrm{N}=129$ ); $52 \%$ of infants were boys (available $\mathrm{N}=142$ ). One infant had neonatal encephalopathy and died 6 hours after delivery; the mother had received no DMT in the year before conception, and her only pregnancy complication was an uncomplicated urinary tract infection in the second trimester. Mothers breastfed after 136 of the 146 live births; this breastfeeding was exclusive for at least 3 months in 51 pregnancies.

\section{Live-Birth Pregnancies: MS Inflammatory Activity During and After Pregnancy}

In the year before pregnancy, for the 146 live-birth pregnancies, the mean baseline ARR (95\% CI [confidence interval]) was $0.33(0.24-0.45)$. This increased in the final trimester before pregnancy, when a clinical relapse occurred in 17 of 146 pregnancies: 4 women had not received DMT in the previous year, 5 had discontinued DMT in anticipation of conception (including fingolimod or natalizumab in 2), and 8 experienced breakthrough activity while on DMT (glatiramer acetate, interferon- $\beta$, fingolimod, or natalizumab). In the 48 live-birth pregnancies in which DMT was discontinued in anticipation of conception, a clinical relapse occurred in 7 (15\%) between DMT discontinuation and conception.

During pregnancy, mean ARR decreased beginning in the first trimester and significantly so in the third trimester $(0.10$ $[0.00-0.26], p=0.017)$, compared with the year before pregnancy (overall effect of time period on ARR $p=0.004$ ). Among the 19 pregnancies with a relapse during pregnancy, 7 (39\%) occurred in women who discontinued fingolimod or natalizumab; each of these relapses occurred within the second or third trimester, comprising $64 \%$ of relapses in this period.

Postpartum, the ARR in the first trimester (months 1-3) was higher $(0.61[0.40-0.93], p=0.012)$ than that of the year before pregnancy and thereafter decreased to prepregnancy levels. Altogether, $17 \%$ women had at least one relapse in the first 3 months postpartum (available $\mathrm{N}=145$ ), and $38 \%$ over the entire year postpartum (available $\mathrm{N}=130$ ) (table 2, figure 1). In sensitivity analyses, excluding pregnancies before 2010 did not affect the results; however, excluding pregnancies in women treated with fingolimod or natalizumab before conception $(\mathrm{N}=24)$ resulted in a lower ARR $(0.50[0.30-0.82])$ in the first trimester postpartum; this did not reach statistical significance compared with the year prepregnancy $(p=0.12)$.

We then evaluated postpartum MRI activity. Among the 70 pregnancies with an MRI performed both in the year before conception and in the year postpartum, the overall proportion of brain MRIs demonstrating new T2 hyperintense lesions was stable across all three-month periods before pregnancy. However, MRI activity increased in the year postpartum: 31 (52\%) pregnancies had at least one "active" MRI (new T2 $\pm \mathrm{Gd}+$ ) in the year postpartum compared with $19(32 \%)$ in the year before conception $(\mathrm{N}=59$ evaluated for both $\mathrm{T} 2$ and $\mathrm{Gd}+)(p<0.001)$. Overall, in the entire year postpartum, 35 pregnancies $(50 \%)$ showed new T2 lesions compared with 18 (30\%) in the previous year $(\mathrm{N}=60$ pregnancies with a previous MRI to evaluate for $\mathrm{T} 2$ lesions, $p<0.001)$ and $21(30 \%)$ showed Gd + lesions compared with $17(25 \%)$ in the previous year $(\mathrm{N}=69$ pregnancies with gadolinium MRIs, $p=0.17$ ) (table 3). 
Table 1 Characteristics of the Study Cohort Relative to Each Pregnancy ( $\mathrm{N}=155$ Pregnancies)

\begin{tabular}{|c|c|}
\hline \multicolumn{2}{|l|}{ Before conception } \\
\hline No. of women & 119 \\
\hline No. of pregnancies & 155 \\
\hline \multicolumn{2}{|l|}{ Disease course at conception, $n$} \\
\hline Healthy ${ }^{a}$ & 1 \\
\hline Clinically isolated syndrome & 9 \\
\hline Relapsing-remitting & 145 \\
\hline Age at conception, mean years \pm SD & $33 \pm 5$ \\
\hline $\begin{array}{l}\text { Disease duration at conception, median years, } \\
\text { IQR (range) }\end{array}$ & $6,3-9(0.5-20)$ \\
\hline $\begin{array}{l}\text { EDSS in year before conception, median, IQR } \\
\text { (range) }^{c}\end{array}$ & $\begin{array}{l}2.0,1.0-2.5 \\
(0.0-6.0)\end{array}$ \\
\hline $\begin{array}{l}\text { Annualized relapse rate before conception, mean } \\
(95 \% \mathrm{Cl})\end{array}$ & $0.37(0.27-0.47)$ \\
\hline \multicolumn{2}{|l|}{ DMT use in year before conception, $n$ (\%) } \\
\hline Glatiramer acetate & $34(22)$ \\
\hline Interferon- $\beta$ s & $28(18)$ \\
\hline Dimethyl fumarate & $10(6)$ \\
\hline Fingolimod & $13(8)$ \\
\hline Natalizumab & $12(8)$ \\
\hline Rituximab & $10(6)$ \\
\hline Ocrelizumab & $2(1)$ \\
\hline No use & $46(30)$ \\
\hline Gravidity before conception, median, IQR (range) & $1,0-1(0-7)$ \\
\hline Parity before conception, median, IQR (range) & $0,0-1(0-4)$ \\
\hline No. of pregnancies using ART & 24 \\
\hline
\end{tabular}

Postpartum

\begin{tabular}{ll}
\hline Pregnancy outcomes, $\mathbf{n}$ & \\
\hline Term & 133 \\
\hline Preterm & 13 \\
\hline Stillbirth & 1 \\
\hline Spontaneous abortion & 6 \\
\hline Elective termination & 2 \\
\hline EDSS in year postpartum, median, IQR (range) & $\mathbf{d}$ \\
\hline $\begin{array}{l}\text { Time to postpartum DMT initiation, median } \\
\text { months, IQR (range) }\end{array}$ & $1.5(1.0,2.0)$ \\
\hline DMT use in the year postpartum, $\mathbf{n}(\%)^{\mathbf{f}}$ & $5.5,3.6-7.8$ \\
\hline Glatiramer acetate & $(0.5-12.3)$ \\
\hline Interferon- $\boldsymbol{\beta} s$ & $23(16)$ \\
\hline Dimethyl fumarate & $15(10)$ \\
\hline
\end{tabular}

Table 1 Characteristics of the Study Cohort Relative to Each Pregnancy ( $\mathrm{N}=155$ Pregnancies) (continued)

\begin{tabular}{ll}
\hline Fingolimod & $13(9)$ \\
\hline Teriflunomide & $1(1)$ \\
\hline Natalizumab & $11(7)$ \\
\hline Rituximab & $15(10)$ \\
\hline Ocrelizumab & $9(6)$ \\
\hline No use & $48(33)$ \\
\hline
\end{tabular}

Abbreviations: $\mathrm{ART}=$ assisted reproductive technologies; $\mathrm{Cl}=$ confidence interval; DMT = disease-modifying therapy; EDSS = Expanded Disability Status Scale; IQR = interquartile range.

${ }^{a} \mathrm{~N}=1$, Clinically Isolated Syndrome diagnosed with clinical event in third trimester of pregnancy.

${ }^{\mathrm{b}}$ Excluding 1 individual with disease onset in pregnancy.

c Information available for 121 pregnancies.

d Information available for 109 pregnancies.

e Delivery date and postpartum DMT start date available for 33 pregnancies.

${ }^{f}$ The first DMT used during the period for which there was postpartum follow up in live-birth pregnancies.

We then evaluated for a relationship between MRI activity and clinical relapse using all postpartum MRIs collected $(\mathrm{N}=137$ for 105 pregnancies, figure 2 and table e-1, lww.com/NXI/A414). Of the 64 relapses experienced in the year postpartum, only 34 had accompanying brain MRIs completed within \pm 60 days of onset of new symptoms; $78 \%$ of these showed new T2 lesions $(\mathrm{N}=32$ with a previous MRI to enable identification of new T2 lesions) and $68 \%$ of these showed $\mathrm{Gd}+$ lesions. There was a significant relationship between the occurrence of a clinical relapse and the observation of a new $\mathrm{Gd}+$ lesion on MRI within \pm 60 days (figure $2)$, for the first trimester postpartum $(p<0.001$, odds ratio [OR] = $30.0,95 \%$ CI [4.6-194.3]) and the entire postpartum year $(p<$ $0.001, \mathrm{OR}=21.1,95 \%$ CI [7.8-57.0]). Furthermore, of the 137 postpartum brain MRIs completed, 107 were completed for monitoring purposes, i.e., in the absence of clinical relapse (figure 2; 104 received gadolinium and had previous MRI for evaluation of new T2 lesions). Among these monitoring MRIs in the postpartum year (figure 2) and 32\% revealed new T2 lesions (33/ $104)$, and $11 \%$ revealed $\mathrm{Gd}+$ lesions (11/104); altogether, $33 \%$ had active MRIs (33/101 evaluated for both T2 and Gd+). For 4 pregnancies, postpartum monitoring MRIs were followed by clinical relapse within 60 days (figure 2); these showed both new $\mathrm{T} 2$ and $\mathrm{Gd}+$ lesions $(\mathrm{N}=2)$, new $\mathrm{T} 2$ lesions only $(\mathrm{N}=1)$ and no changes $(\mathrm{N}=1)$. Overall, $31 \%$ of MRIs performed for postpartum monitoring with no associated clinical relapse within 60 days were "active" ( $\mathrm{N}=97$ evaluated for both T2 and Gd+; figure 2).

\section{EDSS Progression}

Median (IQR) EDSS at evaluation closest to 12 months postpartum for live-birth pregnancies (mean [SD] of 5.8 [4.0] months since delivery) was 1.5 (1.0-2.0) (available $\mathrm{N}=109)$. Among the 99 pregnancies with both preconception and postpartum EDSS scores available, 15 women (16\%) experienced a clinically meaningful increase in EDSS after delivery compared with preconception. 
Table 2 MS Relapses During Pregnancy and Postpartum in Live-Birth Pregnancies (N = 146 Pregnancies for 113 Women)

\begin{tabular}{|c|c|c|c|c|}
\hline Period & No. of pregnancies ${ }^{a}$ & No. of pregnancies with $\geq 1$ relapse & ARR (mean, 95\% Cl) & $p$ Value $^{b}$ \\
\hline Year before conception & 146 & 54 & $0.33(0.24-0.45)$ & Ref \\
\hline \multicolumn{5}{|l|}{ Pregnancy } \\
\hline First trimester & 146 & 8 & $0.19(0.10-0.40)$ & 0.16 \\
\hline Second trimester & 146 & 7 & $0.17(0.08-0.36)$ & 0.09 \\
\hline Third trimester & 146 & 4 & $0.10(0.04-0.26)$ & 0.02 \\
\hline \multicolumn{5}{|l|}{ Year postpartum } \\
\hline Months 1-3 & 145 & 25 & $0.61(0.40-0.93)$ & 0.01 \\
\hline Months 4-6 & 140 & 14 & $0.36(0.21-0.62)$ & 0.81 \\
\hline Months 7-9 & 133 & 13 & $0.35(0.20-0.61)$ & 0.89 \\
\hline Months $10-12$ & 127 & 12 & $0.33(0.19-0.60)$ & 0.98 \\
\hline
\end{tabular}

Abbreviations: ARR = annualized relapse rate; $\mathrm{Cl}=$ confidence interval.

$p$ values $<0.05$ are bold to indicate significance.

a Number of pregnancies followed for the entire three-month period. Only relapses in these pregnancies are included.

${ }^{\mathrm{b}}$ Comparison to ARR during year before pregnancy; $p$-values are calculated from a mixed-effects negative binomial regression with a random person-specific relapse rate; ARR was calculated from the model and parameterized as exp(constant + beta) for each time period. Overall effect of time period on ARR: $p=0.004$.

Predictors of Clinical and Radiographic Activity After Live Births

\section{Clinical Activity}

In univariable analyses, the odds of having at least one clinical relapse during the first trimester postpartum was increased with the occurrence of $\geq 1$ relapse during pregnancy (OR 6.2, 95\% CI 2.2-17.5, $p<0.001)$ and reduced with exclusive breastfeeding for 3 months (OR 0.3 , 95\% CI $0.1-0.9, p=0.03$ ) compared with nonexclusive breastfeeding (table 4). Restricting the analyses to visits occurring between 2013 and 2018
( $\mathrm{N}=20$ clinical relapses for 110 pregnancies) did not affect the significance of the results (occurrence of $\geq 1$ relapse during pregnancy: OR $6.8,95 \%$ CI 2.2-21.6, $p<0.001$; exclusive breastfeeding: OR $0.2,95 \%$ CI $0.03-0.7, p=0.02$ ).

\section{MRI Activity}

In univariable analyses, there was no statistically significant association between new $\mathrm{Gd}+$ lesions in the first trimester postpartum and any of our selected predictors (table 5). However, both relapses during pregnancy, and not exclusively breastfeeding, showed

Figure 1 Annualized Relapse Rate Before, During and After Pregnancies That Resulted in Live Births ( $N=146$ pregnancies)

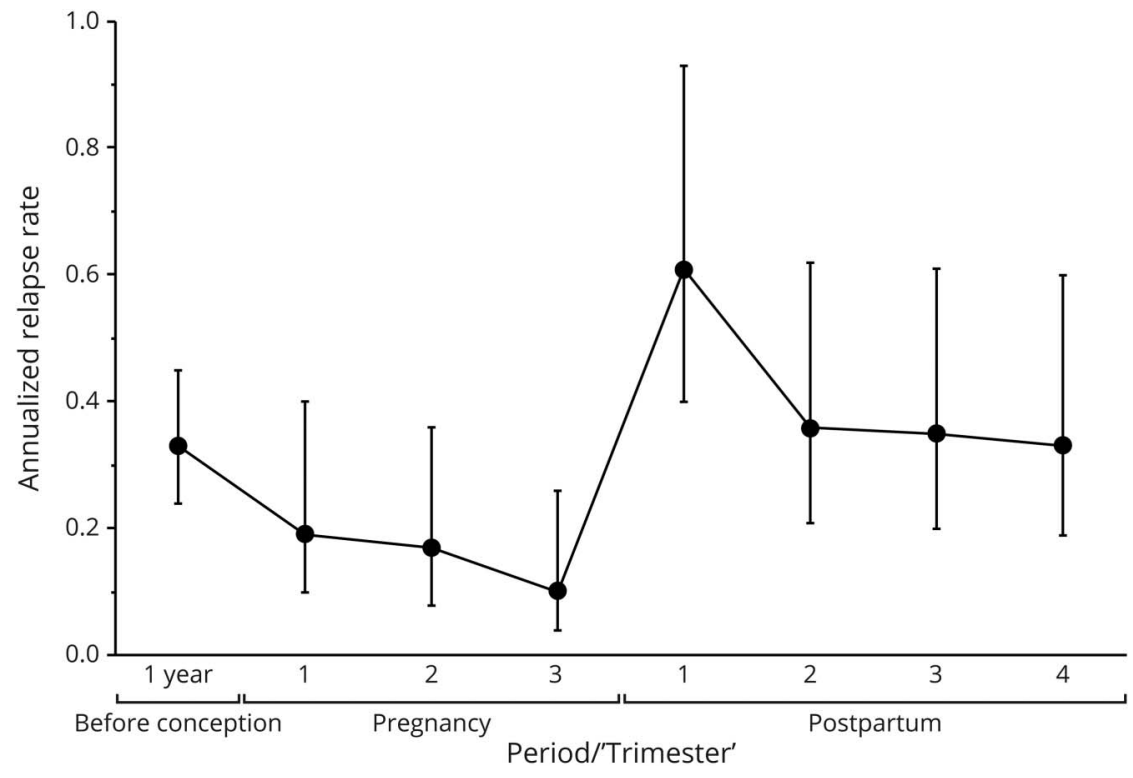

The $x$-axis denotes each trimester (3-month period) before, during, and after pregnancy. Error bars represent $95 \%$ confidence intervals estimated with mixed-effects negative binomial regression. Only pregnancies for which the patient was followed for the entire three-month period were included (see Table 2 for $\mathrm{N}$ in each trimester). 
Table 3 Disease Activity on Brain MRIs in 70 Live-Birth Pregnancies ( $N=59$ Women) With MRI Performed in the Year Before Pregnancy and the Postpartum Year

\begin{tabular}{|c|c|c|c|c|c|c|c|c|c|}
\hline Period & $\begin{array}{l}\text { No. of } \\
\text { pregnancies } \\
\text { evaluated } \\
\text { for new T2 } \\
\text { lesions }^{\mathrm{a}}\end{array}$ & $\begin{array}{l}\text { No. of } \\
\text { pregnancies } \\
\text { with new T2 } \\
\text { lesions (n } \\
\text { [\%]) }\end{array}$ & $\begin{array}{l}p \\
\text { Value }^{b, d}\end{array}$ & $\begin{array}{l}\text { No. of } \\
\text { pregnancies } \\
\text { with Gd } \\
\text { given }\end{array}$ & $\begin{array}{l}\text { No. of } \\
\text { pregnancies } \\
\text { with Gd } \\
\text { lesions ( } \\
\text { [\%]) }\end{array}$ & $\begin{array}{l}p \\
\text { Value }^{b, d}\end{array}$ & $\begin{array}{l}\text { No. of } \\
\text { pregnancies } \\
\text { evaluated } \\
\text { for both new } \\
\text { T2 and Gd } \\
\text { lesions }\end{array}$ & $\begin{array}{l}\text { No. of } \\
\text { pregnancies } \\
\text { with new T2 } \\
\text { and/or Gd } \\
\text { lesions ( } \mathrm{n} \\
\text { [\%]) }\end{array}$ & $\begin{array}{l}p \\
\text { Value }^{c, d}\end{array}$ \\
\hline $\begin{array}{l}\text { Year before } \\
\text { conception }\end{array}$ & 60 & $18(30)$ & Ref & 69 & $17(25)$ & Ref & 59 & $19(32)$ & Ref \\
\hline $\begin{array}{c}\text { Months } \\
1-3\end{array}$ & 21 & $9(43)$ & - & 25 & $7(28)$ & - & - & - & - \\
\hline $\begin{array}{l}\text { Months } \\
4-6\end{array}$ & 11 & $2(18)$ & - & 12 & $2(17)$ & - & - & - & - \\
\hline $\begin{array}{l}\text { Months } \\
7-9\end{array}$ & 24 & $6(25)$ & - & 24 & $3(12)$ & - & - & - & - \\
\hline $\begin{array}{r}\text { Months } \\
10-12\end{array}$ & 20 & $5(25)$ & - & 23 & $5(22)$ & - & - & - & - \\
\hline $\begin{array}{l}\text { Year } \\
\text { postpartum }\end{array}$ & 70 & $35(50)$ & $<0.001$ & 70 & $21(30)$ & 0.17 & 59 & $31(52)$ & $<0.001$ \\
\hline $\begin{array}{c}\text { Months } \\
1-3\end{array}$ & 32 & $13(43)$ & - & 34 & $9(26)$ & - & - & - & - \\
\hline $\begin{array}{l}\text { Months } \\
4-6\end{array}$ & 21 & $11(52)$ & - & 20 & $4(20)$ & - & - & - & - \\
\hline $\begin{array}{l}\text { Months } \\
7-9\end{array}$ & 22 & $9(40)$ & - & 22 & $11(50)$ & - & - & - & - \\
\hline $\begin{array}{r}\text { Months } \\
10-12\end{array}$ & 18 & $8(44)$ & - & 18 & $2(11)$ & - & - & - & - \\
\hline
\end{tabular}

Abbreviations: Gd+ = gadolinium enhancing.

$p$ values $<0.05$ are bold to indicate significance.

${ }^{\mathrm{N}}$ reflects no. of pregnancies with MRI that had a comparison or baseline MRI to allow for evaluation of new T2 lesions.

${ }^{\mathrm{b}} p$-values calculated with conditional logistic regression.

${ }^{c} p$-values calculated with conditional logistic regression, $\mathrm{N}=59$ pregnancies with evaluation for both T2 and Gd+ lesions in the year prior to conception and the year postpartum.

dConditional logistic regression was only performed for the entire year postpartum due to small sample size in individual "trimesters."

a trend toward increased odds of new Gd+ lesions in the first trimester postpartum $(0.05<p<0.10)$. Point estimates suggested increased odds of a postpartum $\mathrm{Gd}+$ lesion in women with relapse in pregnancy and decreased odds in women exclusively breastfeeding. Restricting the analyses to visits occurring between 2013 and 2018 did not affect the significance of the results.

\section{Selected Clinical Scenarios}

\section{Prophylactic Steroids}

Monthly prophylactic steroids were administered in the first 3 months postpartum for 10 pregnancies; women did not breastfeed in 4 . Among the 6 women receiving steroids in the setting of at least 3 months of breastfeeding (exclusively $[\mathrm{N}=$ $5]$, nonexclusively $[\mathrm{N}=1]$ ), none relapsed, and one exclusively breastfeeding had new T2 and Gd+ lesions on brain MRIs completed within the first 6 months postpartum.

\section{Early Initiation of DMT Postpartum}

Of 35 women resuming DMT (including anti-CD20 mAbs) within 3 months of delivery, 33 were followed for the first 2 trimesters postpartum. Five experienced relapses after resuming glatiramer acetate $(15 \%$; 1 relapse in 3 pregnancies and
2 relapses in 2 pregnancies). Of 13 MRIs completed within this period, 7 demonstrated new T2 lesions and 2Gd+ lesions; women with MRI activity were on either interferon- $\beta$ or glatiramer acetate. We did not find a statistically significant difference in ARR or proportion with Gd+ lesions on brain MRI in the second or third trimesters postpartum for women who started DMT in the first 3 months after delivery vs those who did not.

\section{Treatment With Anti-CD20 mAbs}

Of 12 anti-CD20-associated pregnancies, in 10, the mothers were infused within 6 months of conception; 8 resulted in live births; 1 in spontaneous abortion (rituximab; case occurred after a previous case series ${ }^{19}$ ); and 1 in stillbirth (ocrelizumab; details not available). In 2 additional pregnancies, rituximab infusion occurred $>6$ months before conception: 1 (infusion 30 weeks before) resulted in a spontaneous abortion at 10 weeks gestational age, 1 (infusion 10 months before) resulted in a healthy, term live-birth, but a clinical relapse occurred in the second trimester of pregnancy. Postpartum, the mother opted to nonexclusively breastfeed off DMT; she experienced 3 clinical relapses with several new T2 lesions demonstrated on MRI in the third trimester postpartum. 


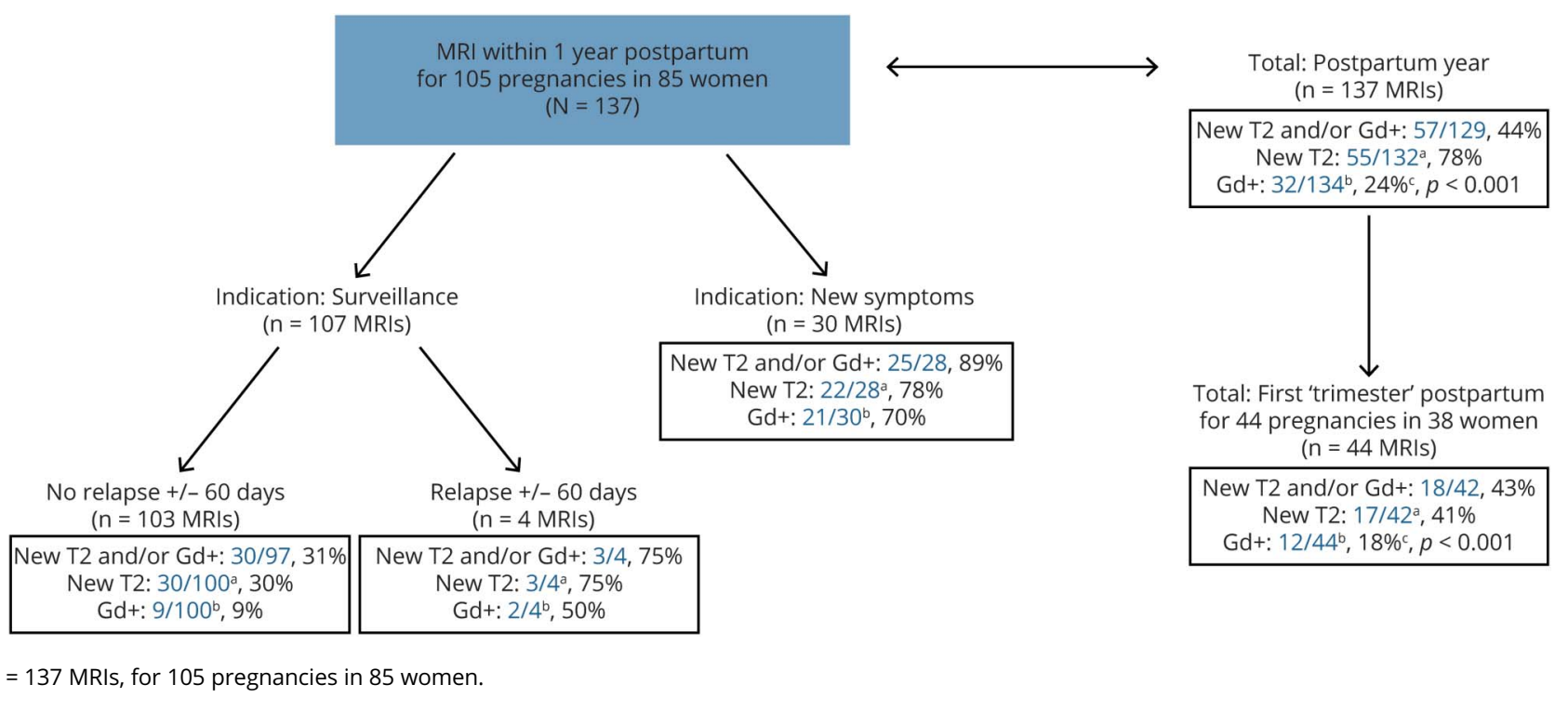

In the 8 live-birth pregnancies with anti-CD20 treatment in the 6 months before conception ( $\mathrm{N}=7$ rituximab, $\mathrm{N}=1$ ocrelizumab), none of the mothers experienced a relapse between treatment and conception or during pregnancy. All 8 were retreated with antiCD20 mAbs within 12 months from delivery; none experienced a clinical relapse during the year postpartum. Of the 7 who underwent an MRI in the year postpartum, one had a new T2 lesion before retreatment (compared with an MRI dated more than a year before conception); none had Gd + lesions postpartum.

\section{Discussion}

Increased MS-related clinical relapse activity after pregnancy has been reported for over 20 years, ${ }^{6}$ but its association with MRI activity has been incompletely assessed. In the current study of women with low disability (median EDSS of 2.0), we advance these clinical findings by showing that these clinical symptoms were significantly associated with MRI activity (vs nondemyelinating etiologies) and that radiologic activity was significantly increased in the postpartum period compared with the year before conception. Furthermore, radiologic disease activity was frequent in the postpartum year even on MRIs performed for surveillance purposes; almost one third of surveillance MRIs demonstrated new T2 hyperintense and/or gadolinium enhancing lesions. Exclusive breastfeeding seemed to reduce the odds of early postpartum gadolinium enhancing lesions. We secondarily confirmed previous reports of increased risk of relapse activity postpartum, which was decreased by exclusive breastfeeding for at least 3 months and of a loss of the protective effect of pregnancy on relapses in women discontinuing fingolimod and natalizumab. ${ }^{7,20}$

Recently, the question has been raised whether changes in MS clinical diagnosis and management (including recent revisions to the McDonald Criteria that allow for earlier diagnosis and DMT initiation $^{21}$ and widespread use of DMTs) have resulted in a more benign disease course less likely to have increased postpartum inflammatory disease activity. ${ }^{8}$ However, in our low-disability cohort of women with mean age 33 years, median EDSS of 2.0 and $70 \%$ with DMT use before pregnancy, we confirmed an elevated rate of relapses postpartum, and this was not associated with preconception ARR. Interestingly, postpartum relapses were not significantly related to DMT use preconception, possibly because of broader clinical trends toward avoiding long periods off DMT and mitigating rebound risk after fingolimod and natalizumab. This odds of postpartum relapse was, however, decreased by exclusive breastfeeding for at least 3 months, consistent with previous reports and a meta-analysis. ${ }^{9,10,17,22}$ Relapse during pregnancy was the only other statistically significant predictor of relapses in the first trimester postpartum. ${ }^{5}$ Early postpartum DMT resumption was not associated with reduced odds of postpartum relapse. However, all DMTs were combined, and we categorized early DMT resumption as use or no use any time between delivery and 3 months postpartum, which did not allow for timedependent analysis, limiting conclusions that can be drawn.

In addition to evaluating clinical and radiologic disease activity postpartum and predictors of these, we further probed common clinical scenarios potentially influencing postpartum inflammatory activity. Women who exclusively breastfed for at least 3 months experienced a lower rate of clinical relapse. In the small subset of 10 women treated with anti-CD20 mAb therapies within 6 months of conception in this cohort and within 12 months of delivery, none experienced clinical relapses or $\mathrm{Gd}+$ lesions during pregnancy or postpartum.

The current study has important limitations. Our overall sample size, although in line with other published cohorts, limited statistical evaluation of some of the observed relationships. This is particularly the case in analyses of predictors 
Table 4 Predictors of at Least One Relapse in the First Trimester Postpartum After Live Births ( $N=145$ Pregnancies for 112 Women; $N=25$ Pregnancies With Clinical Relapse in the First Trimester)

\begin{tabular}{|c|c|c|c|}
\hline Variable & OR & $95 \% \mathrm{Cl}$ & $p$ Value $^{a}$ \\
\hline \multicolumn{4}{|l|}{ Univariable analysis } \\
\hline Disease duration (per 1-year increase) ${ }^{b}$ & 1.1 & $0.9-1.1$ & 0.91 \\
\hline Maternal age at the time of conception (per 1-year increase) & 0.9 & $0.8-1.0$ & 0.10 \\
\hline ARR before pregnancy (per 1-unit increase) & 1.5 & $0.8-2.7$ & 0.21 \\
\hline \multicolumn{4}{|l|}{ Relapses during pregnancy } \\
\hline No relapse & 1 (ref) & & \\
\hline$\geq 1$ relapse & 6.2 & $2.2-17.5$ & $<0.001$ \\
\hline \multicolumn{4}{|l|}{ DMT use in year before conception } \\
\hline No use & 1 (ref) & & \\
\hline Any use & 1.8 & $0.6-5.3$ & 0.25 \\
\hline \multicolumn{4}{|l|}{ Initiation of DMT in 3 months postpartum } \\
\hline No use & 1 (ref) & & \\
\hline Any use & 0.7 & $0.4-2.2$ & 0.60 \\
\hline \multicolumn{4}{|l|}{ Prophylactic steroids in 3 months postpartum } \\
\hline No use & 1 (ref) & & \\
\hline Any use & 1.2 & $0.2-6.1$ & 0.81 \\
\hline \multicolumn{4}{|l|}{ Breastfeeding in 3 months postpartum } \\
\hline Nonexclusive & 1 (ref) & & \\
\hline Exclusive & 0.3 & $0.1-0.9$ & 0.03 \\
\hline \multicolumn{4}{|c|}{$\begin{array}{l}\text { Abbreviations: } \mathrm{ARR}=\text { annualized relapse rate; } \mathrm{Cl}=\text { confidence interval; } \mathrm{DMT}=\text { disease modifying therapy; } \mathrm{OR}=\text { odds ratio. } \\
p \text { values }<0.05 \text { are bold to indicate significance. } \\
\text { a } p \text { value is } 2 \text {-tailed from logistic regression models. } \\
\text { b } \mathrm{N}=144 \text {, one mother excluded due to first clinical demyelinating event in the third trimester of pregnancy. }\end{array}$} \\
\hline
\end{tabular}

of postpartum radiologic activity, given the limited number of MRIs obtained. Our primary analyses evaluated changes in MRI activity postpartum; we did not perform Bonferroni corrections or otherwise adjust for multiple comparisons for our exploratory analyses. The low number of outcome events in our cohort resulted in odds ratios with wide, imprecise CIs that should be cautiously interpreted to identify possible trends and predictors of disease activity. This exploratory study strongly implicates the need for more robust, prospective evaluation of the predictors identified. Our center is a large referral center with possible biases toward patients with more disease activity; however, preconception patient age and ARR were similar to those reported from a large health system, and disability was only slightly higher. ${ }^{8}$ Nonetheless, important differences between population-based and referral center-based cohorts highlight the need to follow women prospectively to ensure minimal loss to follow-up and adequate accounting for baseline risk factors. Reliance on clinical reports could have led to underascertainment of relapses both before, during, and after pregnancy. We also relied on clinical notes labeling breastfeeding as explicitly exclusive in the EMR and assumed nonexclusive breastfeeding for all other cases. Although this is consistent with the field (e.g. ${ }^{17}$ ), relying on clinicians' reports and possibly variable definitions of exclusive breastfeeding likely introduced bias, thereby underestimating the protective effect of exclusive breastfeeding. MRIs were not systematically collected at prespecified time points; rather, timing varied by patient, clinician, and insurance. As a consequence, we likely underestimated the true extent of new lesions across the entire year postpartum. Furthermore, there was substantial heterogeneity, for example, in time since DMT discontinuation preconception. Reassuringly, $78 \%$ of postpartum MRIs were performed for surveillance purposes rather than in reaction to a clinical change, and we benefited from standardized UCSF radiology protocols for most patients. In addition, evaluation of predictors of postpartum clinical and radiologic disease activities may be subject to confounding as the low number of outcome events precluded multivariable analyses. Of note, we did not assess for specific mechanisms of immune activation postpartum. ${ }^{23}$ Our patients' low disability precluded analysis of pregnancy experiences of women with more advanced disability (as is the case in most cohorts ${ }^{17,24}$ ). In 
Table 5 Predictors of New Gadolinium Enhancing Lesions on Brain MRIs Performed in the First Trimester Postpartum ( $N=44$ Pregnancies for 38 Women With MRI in the First Trimester Postpartum; N = 12 Pregnancies With New Gadolinium Enhancing Lesion)

\begin{tabular}{|c|c|c|c|}
\hline Variable & OR & $95 \% \mathrm{Cl}$ & $p$ value ${ }^{a}$ \\
\hline \multicolumn{4}{|l|}{ Univariable analysis } \\
\hline Disease duration (per 1-year increase) & 0.9 & $0.7-1.1$ & 0.17 \\
\hline Maternal age at the time of conception (per 1-year increase) & 0.9 & $0.7-1.1$ & 0.10 \\
\hline ARR before pregnancy (per 1-unit increase) & 0.9 & $0.4-2.2$ & 0.84 \\
\hline \multicolumn{4}{|l|}{ Relapses during pregnancy } \\
\hline No relapse & 1 (ref) & & \\
\hline$\geq 1$ relapse & 4.8 & $0.9-26.1$ & 0.06 \\
\hline \multicolumn{4}{|l|}{ DMT in year before conception } \\
\hline No use & 1 (ref) & & \\
\hline Any use & 0.6 & $0.2-2.5$ & 0.51 \\
\hline \multicolumn{4}{|l|}{ Gd+ lesion on MRI in the year before conception ${ }^{b}$} \\
\hline No & 1 (ref) & & \\
\hline Yes & 3.2 & $0.6-16.5$ & 0.16 \\
\hline \multicolumn{4}{|l|}{ Initiation of DMT in 3 months postpartum } \\
\hline No use (before MRI) & 1 (ref) & & \\
\hline Any use (before MRI) & 1.1 & $0.2-6.5$ & 0.93 \\
\hline \multicolumn{4}{|l|}{ Prophylactic steroids in 3 months postpartum } \\
\hline No use (before MRI) & 1 (ref) & & \\
\hline Any use (before MRI) & 0.7 & $0.1-4.5$ & 0.72 \\
\hline \multicolumn{4}{|l|}{ Breastfeeding in 3 months postpartum } \\
\hline Nonexclusive (before and at time of MRI) & 1 (ref) & & \\
\hline Exclusive (before and at time of MRI) & 0.3 & $0.1-1.1$ & 0.07 \\
\hline $\begin{array}{l}\text { Abbreviations: } \mathrm{ARR}=\text { annualized relapse rate; } \mathrm{Cl}=\text { confidence interv } \\
\text { a } p \text { value is 2-tailed from logistic regression models. } \\
{ }^{b} \mathrm{~N}=34 \text { with available MRI in the year prior to conception; among th }\end{array}$ & $\begin{array}{l}\text { nodifyin } \\
=12 \mathrm{won}\end{array}$ & $\begin{array}{l}\text { dolinium e } \\
\text { esion. }\end{array}$ & ss ratio. \\
\hline
\end{tabular}

these women, decision-making ${ }^{25}$ and physiologic factors could result in different disease outcomes. Finally, although pregnancy losses did not represent a focus of the current study, we likely underascertained the frequency of early pregnancy loss, which may have occurred between 2 clinical visits.

Our observations have several important implications. The association between clinical and radiographic inflammatory changes improved our confidence that clinical relapses reported in our, and likely also others', cohorts do reflect underlying inflammatory activity. Our observations also support a now-widely reported protective effect of breastfeeding. In clinical practice, the presence of inflammatory lesions in patients who are not suspected of clinical relapses underscores the importance of obtaining routine early postpartum MRIs to monitor women who have not resumed highly effective DMTs. Indeed, postpartum MRI inflammatory activity may not always lead to clinical relapses with their own immediate effects on clinical disability, but demyelinated axons are nonetheless vulnerable to neurodegeneration and progressive clinical worsening. Presence of asymptomatic new lesions could prompt physicians to consider earlier DMT initiation or a change to more effective DMT in the postpartum period. Although prospective monitoring is needed to clarify which time points would best capture this activity, in our clinical practice, we routinely recommend a baseline MRI before conception attempts, followed by a surveillance MRI in the first trimester postpartum. ${ }^{24,26}$ Overall, management of women in the postpartum period should include strategies to decrease both clinical and radiologic disease activity.

\section{Study Funding}

The authors report no targeted funding. 


\section{Disclosure}

A. Anderson reports no disclosures relevant to the manuscript. K.M. Krysko receives Fellowship support from Biogen. Dr. Rutatangwa receives Fellowship support from Biogen. T. Krishnakumar, W. Rowles, C. Chen, and C. Zhao report no disclosures relevant to the manuscript. $M$. Houtchens reports consulting and advisory board fees from Biogen, EMD-Serono, Genzyme-Sanofi, Novartis, and RocheGenentech. She has received research support from Genzyme-Sanofi, Biogen and Merck. R. Bove has received consulting and advisory board fees from Alexion, Biogen, EMD-Serono, Genzyme-Sanofi, Novartis, Pear Therapeutics, and Roche-Genentech. She has received research support from Akili Therapeutics. Go to Neurology.org/NN for full disclosures.

\section{Publication History}

Received by Neurology: Neuroimmunology \& Neuroinflammation August 14, 2020. Accepted in final form December 14, 2020.

\section{Appendix Authors}

\begin{tabular}{|c|c|c|}
\hline Name & Location & Contribution \\
\hline $\begin{array}{l}\text { Annika } \\
\text { Anderson, BA }\end{array}$ & $\begin{array}{l}\text { University of } \\
\text { California, San } \\
\text { Francisco }\end{array}$ & $\begin{array}{l}\text { Designed and conceptualized the } \\
\text { study, analyzed and interpreted } \\
\text { the data, and drafted the } \\
\text { manuscript for intellectual content }\end{array}$ \\
\hline $\begin{array}{l}\text { Kristen M. } \\
\text { Krysko, MD, } \\
\text { MAS }\end{array}$ & $\begin{array}{l}\text { University of } \\
\text { California, San } \\
\text { Francisco }\end{array}$ & $\begin{array}{l}\text { Major role in the acquisition of } \\
\text { data, interpreted the data, and } \\
\text { revised the manuscript for } \\
\text { intellectual content }\end{array}$ \\
\hline $\begin{array}{l}\text { Alice } \\
\text { Rutatungwa, } \\
\text { DO }\end{array}$ & $\begin{array}{l}\text { University of } \\
\text { California, San } \\
\text { Francisco }\end{array}$ & $\begin{array}{l}\text { Interpreted the data and revised } \\
\text { the manuscript for intellectual } \\
\text { content }\end{array}$ \\
\hline $\begin{array}{l}\text { Tanya } \\
\text { Krishnakumar, } \\
\text { BA }\end{array}$ & $\begin{array}{l}\text { University of } \\
\text { California, San } \\
\text { Francisco }\end{array}$ & $\begin{array}{l}\text { Major role in the acquisition of } \\
\text { data and revised the manuscript } \\
\text { for intellectual content }\end{array}$ \\
\hline $\begin{array}{l}\text { Chelsea Chen, } \\
\text { BA }\end{array}$ & $\begin{array}{l}\text { University of } \\
\text { California, San } \\
\text { Francisco }\end{array}$ & $\begin{array}{l}\text { Major role in the acquisition of } \\
\text { data and revised the manuscript } \\
\text { for intellectual content }\end{array}$ \\
\hline $\begin{array}{l}\text { William } \\
\text { Rowles, BA }\end{array}$ & $\begin{array}{l}\text { University of } \\
\text { California, San } \\
\text { Francisco }\end{array}$ & $\begin{array}{l}\text { Revised the manuscript for } \\
\text { intellectual content }\end{array}$ \\
\hline Chao Zhao, MS & $\begin{array}{l}\text { University of } \\
\text { California, San } \\
\text { Francisco }\end{array}$ & $\begin{array}{l}\text { Revised the manuscript for } \\
\text { intellectual content }\end{array}$ \\
\hline $\begin{array}{l}\text { Maria } \\
\text { Houtchens, } \\
\text { MD, MSc }\end{array}$ & $\begin{array}{l}\text { Brigham and } \\
\text { Women's } \\
\text { Hospital, Boston }\end{array}$ & $\begin{array}{l}\text { Designed and conceptualized the } \\
\text { study and revised the manuscript } \\
\text { for intellectual content }\end{array}$ \\
\hline $\begin{array}{l}\text { Riley Bove, MD, } \\
\text { MSc }\end{array}$ & $\begin{array}{l}\text { University of } \\
\text { California, San } \\
\text { Francisco }\end{array}$ & $\begin{array}{l}\text { Designed and conceptualized the } \\
\text { study, analyzed and interpreted } \\
\text { the data, and revised the } \\
\text { manuscript for intellectual } \\
\text { content }\end{array}$ \\
\hline
\end{tabular}

\section{References}

1. Whitacre CC, Reingold SC, O'Looney PA. A gender gap in autoimmunity. Science 1999;283:1277-1278.

2. Sadovnick AD, Ebers GC. Epidemiology of multiple sclerosis: a critical overview. Can J Neurol Sci 1993;20:17-29.

3. Huang WJ, Chen WW, Zhang X. Multiple sclerosis: pathology, diagnosis and treatments. Exp Ther Med 2017;13:3163-3166.

4. Hellwig K, Haghikia A, Rockhoff M, Gold R. Multiple sclerosis and pregnancy: experience from a nationwide database in Germany. Ther Adv Neurol Disord 2012;5: 247-253.

5. Vukusic S, Hutchinson M, Hours M, et al. Pregnancy and multiple sclerosis (the PRIMS study): clinical predictors of post-partum relapse. Brain 2004;127: 1353-1360.

6. Confavreux C, Hutchinson M, Hours MM, Cortinovis-Tourniaire P, Moreau T. Rate of pregnancy-related relapse in multiple sclerosis. Pregnancy in Multiple Sclerosis Group. N Engl J Med 1998;339:285-291.

7. Alroughani R, Alowayesh MS, Ahmed SF, Behbehani R, Al-Hashel J. Relapse occurrence in women with multiple sclerosis during pregnancy in the new treatment era. Neurology 2018;90:e840-e846.

8. Langer-Gould A, Smith J, Albers K, et al. Pregnancy-related relapses in a large, contemporary multiple sclerosis cohort: No increased risk in the postpartum period [abstract]. Neurology 2020;94:e1939-e1949.

9. Langer-Gould A, Huang SM, Gupta R, et al. Exclusive breastfeeding and the risk of postpartum relapses in women with multiple sclerosis. Arch Neurol 2009;66: 958-963.

10. Hellwig K, Rockhoff M, Herbstritt S, et al. Exclusive breastfeeding and the effect on postpartum multiple sclerosis relapses. JAMA Neurol 2015;72:1132-1138.

11. Digre KB. Headaches during pregnancy. Clin Obstet Gynecol 2013;56:317-329.

12. van Slobbe AM, Bohnen AM, Bernsen RM, Koes BW, Bierma-Zeinstra SM. Incidence rates and determinants in meralgia paresthetica in general practice. J Neurol 2004; 251:294-297.

13. Schned ES. DeQuervain tenosynovitis in pregnant and postpartum women. Obstet Gynecol 1986;68:411-414.

14. Paavilainen T, Kurki T, Parkkola R, et al. Magnetic resonance imaging of the brain used to detect early post-partum activation of multiple sclerosis. Eur J Neurol 2007; 14:1216-1221.

15. Lebrun C, Le Page E, Kantarci O, et al. Impact of pregnancy on conversion to clinically isolated syndrome in a radiologically isolated syndrome cohort. Mult Scler 2012;18: $1297-1302$.

16. van Walderveen MA, Tas MW, Barkhof F, et al. Magnetic resonance evaluation of disease activity during pregnancy in multiple sclerosis. Neurology 1994;44:327-329.

17. Krysko KM, Rutatangwa A, Graves J, Lazar A, Waubant E. Association between breastfeeding and postpartum multiple sclerosis relapses: a systematic review and meta-analysis. JAMA Neurol 2020;77:327-338.

18. University of California SFMSET; Cree BAC, Hollenbach JA, Bove R, et al. Silent progression in disease activity-free relapsing multiple sclerosis. Ann Neurol 2019;85: 653-666.

19. Das G, Damotte V, Gelfand JM, et al. Rituximab before and during pregnancy: a systematic review, and a case series in MS and NMOSD. Neurol Neuroimmunol Neuroinflamm 2018;5:e453.

20. Novi G, Ghezzi A, Pizzorno M, et al. Dramatic rebounds of MS during pregnancy following fingolimod withdrawal. Neurol Neuroimmunol Neuroinflamm 2017;4: e377.

21. Portaccio E, Ghezzi A, Hakiki B, et al. Postpartum relapses increase the risk of disability progression in multiple sclerosis: the role of disease modifying drugs. J Neurol Neurosurg Psychiatry 2014;85:845-850.

22. Pakpoor J, Disanto G, Lacey MV, Hellwig K, Giovannoni G, Ramagopalan SV. Breastfeeding and multiple sclerosis relapses: a meta-analysis. J Neurol 2012;259: $2246-2248$

23. Kaplan TB, Bove R. Demyelinating disease and pregnancy. In: O’Neil M, editor. Neurology and Psychiatry of Women. Cham: Springer; 2019:145-156.

24. Bove R, Alwan S, Friedman JM, et al. Management of multiple sclerosis during pregnancy and the reproductive years: a systematic review. Obstet Gynecol 2014;124: $1157-1168$.

25. Alwan S, Yee IM, Dybalski M, et al. Reproductive decision making after the diagnosis of multiple sclerosis (MS). Mult Scler 2013;19:351-358.

26. Krysko KM, Graves JS, Dobson R, et al. Sex effects across the lifespan in women with multiple sclerosis. Ther Adv Neurol Disord 2020;13:1756286420936166. 


\section{Neurology \\ Neuroimmunology \& Neuroinflammation}

Clinical and Radiologic Disease Activity in Pregnancy and Postpartum in MS

Annika Anderson, Kristen M. Krysko, Alice Rutatangwa, et al.

Neurol Neuroimmunol Neuroinflamm 2021;8;

DOI 10.1212/NXI.0000000000000959

This information is current as of February 19, 2021

\section{Updated Information \& Services}

References

Citations

Subspecialty Collections

Permissions \& Licensing

Reprints including high resolution figures, can be found at:

http://nn.neurology.org/content/8/2/e959.full.html

This article cites 25 articles, 4 of which you can access for free at: http://nn.neurology.org/content/8/2/e959.full.html\#\#ref-list-1

This article has been cited by 1 HighWire-hosted articles: http://nn.neurology.org/content/8/2/e959.full.html\#\#otherarticles

This article, along with others on similar topics, appears in the following collection(s):

MRI

http://nn.neurology.org//cgi/collection/mri

Multiple sclerosis

http://nn.neurology.org//cgi/collection/multiple_sclerosis

Information about reproducing this article in parts (figures,tables) or in its entirety can be found online at:

http://nn.neurology.org/misc/about.xhtml\#permissions

Information about ordering reprints can be found online:

http://nn.neurology.org/misc/addir.xhtml\#reprintsus

Neurol Neuroimmunol Neuroinflamm is an official journal of the American Academy of Neurology.

Published since April 2014, it is an open-access, online-only, continuous publication journal. Copyright

Copyright () 2021 The Author(s). Published by Wolters Kluwer Health, Inc. on behalf of the American

Academy of Neurology.. All rights reserved. Online ISSN: 2332-7812.

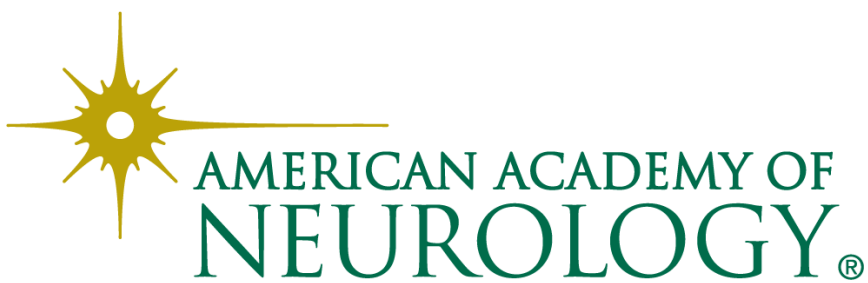

